\title{
Comparative Analysis of Kerf Width Produced on GFRP composite material Using Abrasive Water Suspension Jet Machining by Taguchi Approach
}

\author{
[Deepak D, Anjaiah Devineni]
}

\begin{abstract}
Abrasive Water Suspension Jet (AWSJ) is one of the emerging non-traditional machining tools used in machining of brittle, heat sensitive materials and composites. Usually machining is carried out by the AWS jet in the air. Presence of air around the jet may lead to jet expansion which results in increased kerf width. In the present research work an attempt has been made to investigate the effect of various process parameters on kerf width using AWSJ submerged in water while machining of Glass Fiber Reinforced Plastic (GFRP) composite material. The experimental results indicate that the top kerf width decreases by $3 \%$ during under water machining as compared to that of free air machining.
\end{abstract}

Keywords - AWSJ, Kerf width, Stand off distance, Degree of freedom Introduction (Heading 1)

\section{Introduction}

Advances in research and development of new engineering materials are indispensable to meet the growing needs of industries. To process such materials, it is necessary to develop compatible machining techniques. Components with complex shapes that need to be produced from brittle and heat sensitive materials as well as composites can now be machined by an advanced manufacturing method called Abrasive Water Jet (AWJ) Machining (1 - 5). Abrasive Water Suspension Jet (AWSJ) is one of the variants of AWJ machining in which suspended abrasive particles in a liquid medium called slurry is pressurized and expelled through the nozzle.

Deepak D

Manipal Institute of Technology/ Manipal University India

Devineni Anjaiah

Manipal Institute of Technology/ Manipal University India
Through computer numerical control of jet movement, the work material having complex profiles with better surface quality and precision can be achieved. The benefit of AWSJ over AWJ is the generation of a stable jet with higher power density, which leads to efficient energy transfer to abrasive particles (6-7). In AWSJ machining the abrasive suspension is accelerated through a fine orifice to produce a high velocity coherent jet which is capable of machining wide range of materials.

\section{A. AWSJ Machining - Experimental set up}

The AWSJ machining set up used in the present research work shown in Fig. 1 has been developed indigenously and is based on principle of indirect pumping. Suspension mixture consisting of water, polymer and abrasives is prepared and charged to floating piston cylinder from top end. This suspension is pressurized indirectly to the required pressure by means of high pressure water supplied to the cylinder from the bottom side of the floating piston. The high pressure suspension is expelled through the nozzle with high velocity which is directed on the target material to perform machining. The nozzle movement in $\mathrm{X}$ and $\mathrm{Y}$ directions is controlled by $\mathrm{CNC}$ attachment. The nozzle is made up of a stainless steel body with a tungsten carbide insert at the center having a length of $23 \mathrm{~mm}$ with inlet diameter of $8 \mathrm{~mm}$ and exit diameter of $1.2 \mathrm{~mm}$. The machining arrangement is shown in Fig. 2.

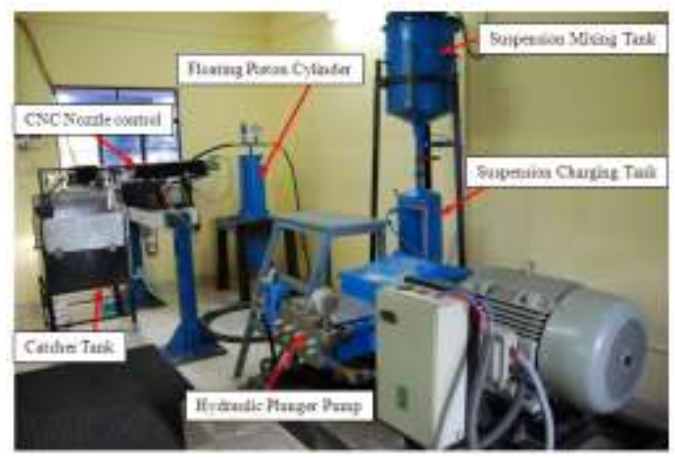

Figure 1: AWSJ machining set up 
Proc. of the Intl. Conf. on Advances in Civil, Structural and Mechanical Engineering - ACSM 2015. Copyright (C) Institute of Research Engineers and Doctors, USA .All rights reserved.

ISBN: 978-1-63248-039-2 doi: 10.15224/ 978-1-63248-039-2-23

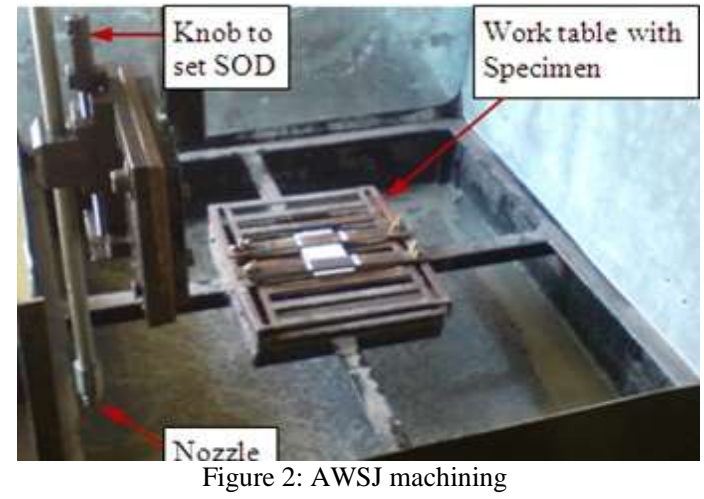

\section{Experimental Design}

In the present research four process parameters namely; abrasive size, Standoff Distance (SOD), abrasive concentration and feed rate are chosen to study their effect on response parameter, i.e., kerf width. The process parameters (input factors) and their levels are listed in Table1. These parameters are selected mainly on the basis of literature review, their importance in AWSJ machining and also setup limitations (8-9). The ranges for these process parameters are chosen from the trial runs. Taguchi designs or Orthogonal Array $(\mathrm{OA})$ designs are selected for the entire experimentation in the present study, as these designs require a minimum number of experiments to be conducted and provide reliable results (10). The selection of a particular OA design mainly depends on the total Degrees of Freedom (DF) which is determined from the number of input factors involved in the experimentation, their levels, and their main effects on the response. The total DF in the present experimentation is 9 (2 $\mathrm{DF}$ for each factor $\mathrm{x} 4$ factors +1 for overall mean). Hence, the standard L9 (34) Orthogonal array given in Table 2 has been selected for the present experimental study. The specification of the GFRP test specimen is shown in Table 3.

TABLE 1: PROCESS PARAMETERS AND THEIR LEVELS

\begin{tabular}{|c|c|c|c|}
\hline \multirow{2}{*}{ Process parameters (input factors) } & \multicolumn{3}{|c|}{ Levels } \\
\cline { 2 - 4 } & 1 & 2 & 3 \\
\hline Abrasive size (microns) & 185 & 125 & 105 \\
\hline Standoff distance (SOD) (mm) & 1 & 3 & 5 \\
\hline Abrasive concentration (weight \%) & 2 & 3 & 4 \\
\hline Feed rate (mm/min) & 100 & 125 & 150 \\
\hline
\end{tabular}

TABLE 2: STANDARD L9 (34) OA WITH FACTOR SETTINGS

\begin{tabular}{|c|c|c|c|c|}
\hline \multirow{2}{*}{$\begin{array}{c}\text { Expt. } \\
\text { No. }\end{array}$} & $\begin{array}{c}\text { Abrasive } \\
\text { size } \\
\text { (microns) }\end{array}$ & $\begin{array}{c}\text { SOD } \\
(\mathrm{mm}) \\
(2)\end{array}$ & $\begin{array}{c}\text { Abrasive } \\
\text { concentration } \\
\text { (weight } \%)\end{array}$ & $\begin{array}{c}\text { Feed rate } \\
(\mathrm{mm} / \mathrm{min}) \\
(4)\end{array}$ \\
\hline 1 & 185 & 1 & 2 & 100 \\
\hline 2 & 185 & 3 & 3 & 150 \\
\hline 3 & 185 & 5 & 4 & 200 \\
\hline 4 & 125 & 1 & 4 & 150 \\
\hline 5 & 125 & 3 & 2 & 200 \\
\hline 6 & 125 & 5 & 3 & 100 \\
\hline 7 & 105 & 1 & 3 & 200 \\
\hline 8 & 105 & 3 & 4 & 100 \\
\hline 9 & 105 & 5 & 2 & 150 \\
\hline
\end{tabular}

TABLE 3: SPECIFICATION OF GFRP TEST SPECIMEN

\begin{tabular}{|l|l|}
\hline Reinforcement & $\begin{array}{l}\text { Bidirectional plain weave }\left[\mathbf{0 - 9 0}^{\mathbf{0}}\right] \\
\text { type glass fibers fabric }\end{array}$ \\
\hline Composition & Epoxy matrix: $56 \%$ and fibers: $44 \%$ \\
\hline Manufacturing & Hand layup, Cured at $120^{\circ}$ for 2 hours \\
\hline Dimensions & $75 \times 50 \times 6 \mathrm{~mm}$ \\
\hline Aerial density & $400 \mathrm{gm} / \mathrm{m}^{2}$ \\
\hline
\end{tabular}

\section{Results and Discussion}

The experiments - with two replications have been conducted by varying the factor settings listed in Table 2 for both free air and under water machining. The responses of top kerf width have been measured using a tool room microscope. The response data is subjected to ANOVA for finding the significant factors at 95\% confidence level and results for the response parameter is shown in Tables 4 . The process parameters that significantly affect top kerf width and surface roughness may be identified by observing the $\mathrm{F} 0(>4)$ values. The ANOVA results presented in Table 4 is summarized in Tables 5 from which it can be identified that all the process parameters except the abrasive concentration are significantly affecting top kerf width and surface roughness in both free air and underwater machining. The percentage contribution of each input factor towards total variation in each of response parameters is also given in Tables 5 .

TABLE 4: ANALYSIS OF VARIANCE FOR TOP KERF WIDTH

\begin{tabular}{|c|l|c|c|r|r|c|c|}
\hline \multirow{2}{*}{ Source } & \multicolumn{4}{|c|}{ Free jet machining } & \multicolumn{3}{c|}{$\begin{array}{c}\text { Under water } \\
\text { machining }\end{array}$} \\
\cline { 2 - 9 } & $D F$ & $S S$ & $M S$ & $F_{0}$ & $S S$ & $M S$ & $F_{0}$ \\
\hline Abrasive size & 2 & 0.1015 & 0.0506 & 4.32 & 0.0218 & 0.0109 & 6.80 \\
\hline Standoff distance & 2 & 0.3334 & 0.1667 & 14.19 & 0.0179 & 0.0089 & 5.60 \\
\hline Abrasive & 2 & 0.0235 & 0.0118 & 1.01 & 0.0032 & 0.0016 & 1.01 \\
\hline Feed rate $(\mathrm{mm} / \mathrm{min})$ & 2 & 0.1793 & 0.0897 & 7.63 & 0.0419 & 0.0209 & 13.1 \\
\hline Error & 2 & 0.0235 & & & 0.0032 & 0.0016 & \\
\hline Total & 8 & 0.6377 & & & 0.08 & & \\
\hline
\end{tabular}


Proc. of the Intl. Conf. on Advances in Civil, Structural and Mechanical Engineering - ACSM 2015. Copyright (C) Institute of Research Engineers and Doctors, USA .All rights reserved.

ISBN: 978-1-63248-039-2 doi: 10.15224/ 978-1-63248-039-2-23

TABLE 5: SIGNIFICANT FACTORS AND THEIR CONTRIBUTION TO VARIATION IN TOP KERF WIDTH

\begin{tabular}{|c|c|c|c|c|}
\hline \multirow{2}{*}{ ZProcess parameters } & \multicolumn{2}{|c|}{$\begin{array}{c}\text { Free jet } \\
\text { machining }\end{array}$} & \multicolumn{2}{c|}{$\begin{array}{c}\text { Under water } \\
\text { machining }\end{array}$} \\
\cline { 2 - 5 } & Remarks & $\%$ SS & Remarks & $\%$ SS \\
\hline Abrasive size (microns) & $\mathrm{S}$ & 15.91 & $\mathrm{~S}$ & 25.66 \\
\hline Stand off distance (mm) & $\mathrm{S}$ & 52.25 & $\mathrm{~S}$ & 21.14 \\
\hline $\begin{array}{c}\text { Abrasive concentration } \\
\text { (wt. \%) }\end{array}$ & $\mathrm{NS}$ & 3.68 & $\mathrm{NS}$ & 3.77 \\
\hline Feed rate (mm/min) & $\mathrm{S}$ & 28.11 & $\mathrm{~S}$ & 49.40 \\
\hline
\end{tabular}

$\mathrm{S}$ - Significant at $95 \%$ confidence level; NS - Not significant

$\% \mathrm{SS}$ - percentage contribution of each factor towards total variation

\section{Effect of process parameters on Top Kerf Width (TKW)}

Fig. 3 and 4 show the main effects plots of TKW for free air and under water machining respectively. Increase in standoff distance results, significant increase in TKW in both machining conditions. This is due to the fact that increase in stand of distance results in jet expansion and hence increases TKW. Further, it is observed from the same plots that, increase in feed rate significantly decreases TKW. Increase in feed rate reduces the number of retracting abrasive particles as well as the time for complete retraction from the machining zone, hence reduces TKW.

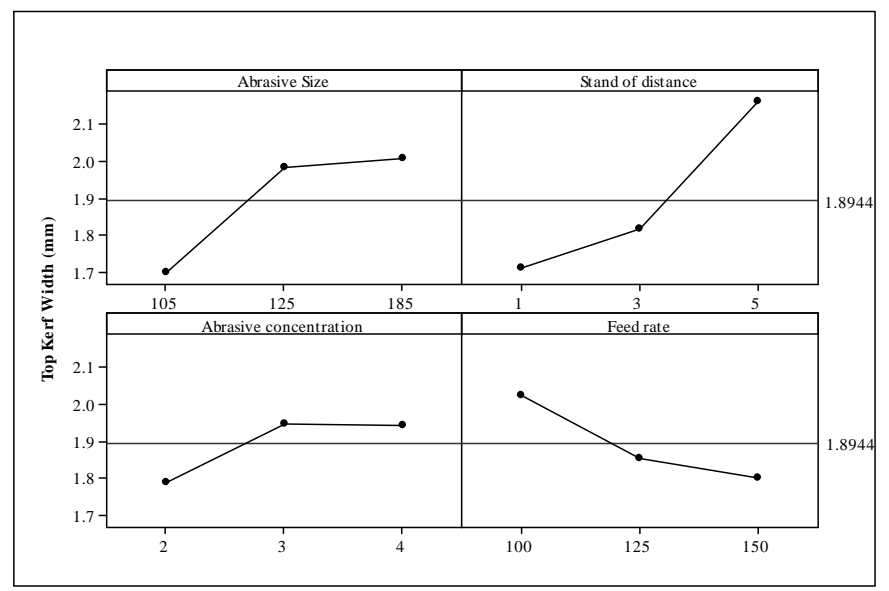

Figure 3: Main Effects Plots of Top Kerf Width (free air machining)

It is seen from the Figure 3 that an increase in abrasive particle size results in increase in TKW in free air machining. The collision between the particles leads jet expansion, the larger the abrasive size the larger will be the jet expansion, hence increases the TKW. But in under water machining, the TKW decreases with increase in abrasive size (Figure 4 top left). This may be due to fact that, the surrounding water column may absorb some of the particle energy which increases the jet coherence. Larger the abrasive size, the energy absorbed by surrounding water column is more, correspondingly more jet coherence, hence decreases TKW. Also, it is seen that increase in abrasive concentration results in marginal increase in TKW in both machining conditions because the range selected for abrasive concentration is not enough to show significant increase in TKW. Figures 5(a) and 5(b) show the TKW produced during machining of the GFRP specimen by AWSJ in free air and under water respectively. It is observed from these Figures that, under water machining produces thinner kerf compared to that of free air machining.

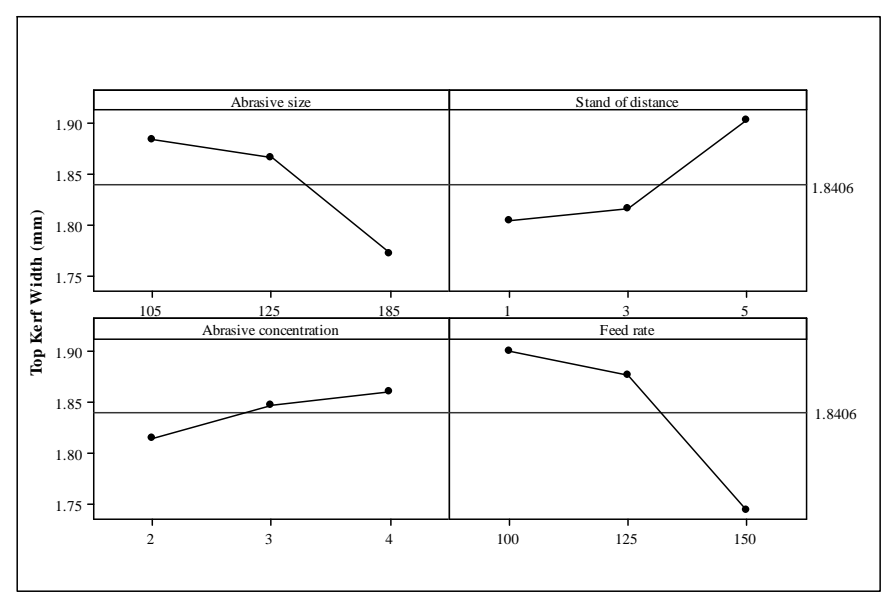

Figure 4: Main Effects Plots of Top Kerf Width (under water machining)

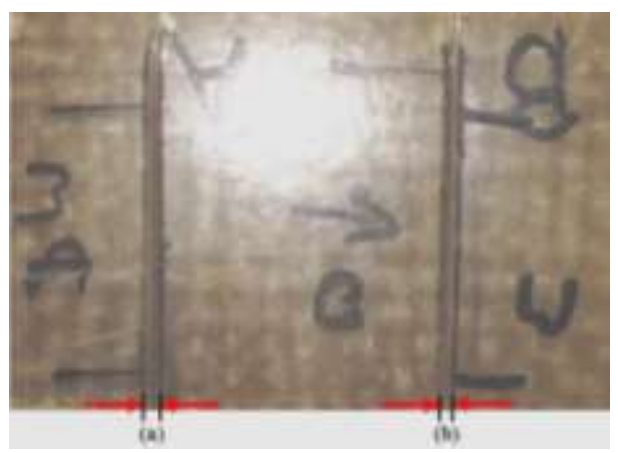

Figure 5: Top Kerf Width of machined GFRP specimen: (a) Free air (b) Under water

\section{v. Conclusions}

Based on the experimental results reported earlier, the following major conclusions have been drawn.

- The experimental results of machining of GFRP composites using AWSJ reveal that the top kerf width increases with increase in standoff distance, abrasive size 
and abrasive concentration, and it decreases with increase in feed rate during free air machining.

- In case of underwater machining, the top kerf width decreases significantly with increase in feed rate and abrasive size. However there is marginal increase in kerf width with increase in abrasive concentration and standoff distance.

- It is observed from the top kerf width decreases by $3 \%$ during under machining as compared to that of free air machining.

\section{References}

[1] M. Hashish, "Comparative Evaluation of Abrasive Liquid Jet Machining Systems", Transactions of the ASME, Journal of Engineering for Industry, vol.115, pp. 44-50, Feb 1993.

[2] M. Ramulu, S. Kunaporn, D. Arola, M Hashish, and J. Hopkins, "Waterjet Machining and Peening of Metals", Transactions of the ASME, Journal of Pressure Vessels Technology, vol. 122, pp. 90-95, Feb 2000

[3] U.A.Khashaba, "Delamination in drilling GFR-thermoset composites", Composite Structures, Vol.63, Issues 3-4, pp 313-327, 2004.

[4] A.M. Abrao , J.C. Campos Rubio, P.E. Faria and J.P. Davim, " The effect of cutting tool geometry on thrust force and delamination when drilling glass fibre reinforced plastic composite", Materials and Design, vol 29, pp 508-513, 2008.

[5] I. El-Sonbaty, U.A. Khashaba, T. Machaly, "Factors affecting the machinability of GFR/epoxy composites", Composite Structures, Vol 63, pp 329-338, 2004.

[6] M. A. Azmir \& A. K. Ahsan \& A. Rahmah, "Effect of abrasive water jet machining parameters on aramid fiber reinforced plastics composite", International journal of material forming, vol 2, pp 37-44, 2009.

[7] T. Nguyen, D.K. Shanmugam and J. Wang, "Effect of liquid properties on the stability of an abrasive waterjet", International Journal of Machine Tools and Manufacture, Volume 48, Issue 10, pp 1138-1147, 2008.

[8] D. Anjaiah, Chincholkar A. M and B. Siddeswarappa, "Effect of process parameters on the material removal rate on Glass in low pressure Abrasive Slurry Jet Machining", in Proc. of National Conference on World class manufacturing, India, 2003, pp 20-24.

[9] D.Anjaiah and Chincholkar A.M, "AWSJ cutting of ceramics - An experimental study of the effect of process parameters on the surface roughness using DOE," Proc. of 9th Pacific Rim International Conference on Water Jetting Technology, Nov 20-23, 2009, Nihon University, Koriyama, Japan, pp 161-169.

[10] Madhav S Phadke, "Quality Engineering Using Robust Design", Prentice Hall Publishers, New Jersey, 1989. 